\title{
Building e-based literacy for vocational education and training students
}

\author{
Elena Verezub, Vittoria Grossi, Kerry Howard and Patricia Watkins \\ Swinburne University of Technology
}

\begin{abstract}
The use of the Internet within educational settings means that the term 'literacy' must be broadened to encompass new skills and reflect the merging of old and new literacy. For practitioners the challenge lies in making new media meaningful and empowering for students. Whilst interacting with hypertext has received much attention over the last two decades, little research has focused on comprehending in the hypertext context. This study investigated and compared the effectiveness of metacognitive reading comprehension strategies training on students' comprehension when reading hypertexts with linear structure containing text, picture or audio links. It was predicted that training students to monitor their comprehension would result in enhanced reading comprehension for a hypertext. In order to verify the hypothesis for the study, pretest, three training sessions and post-tests were conducted with the first year Diploma students studying within the Department of Horticulture and Environmental Science. The results indicated that training to apply metacognitive strategies enhanced comprehension in the hypertext context.
\end{abstract}

\section{Introduction}

Rapid changes in information and communication technology (ICT) have reshaped the meaning of "literacy" and the role of the teacher. The new era of web literacy has not evolved without its critics, some suggesting that it signalled the end of print based materials and the literacy skills associated with them. However, Kellner (2002) has argued that this technological revolution brings the opportunity to reshape literacy skills in education to better serve democratic needs and to prepare citizens for a global multicultural world. Kellner (2002) stresses also that the debate about the role of computers in education should be about how they are used in education not whether they are good or bad.

The use of ICT in learning and teaching will continue as new technological tools are made available for the purpose of education. Policies that promote the use of these are regarded as innovative and important skills not only to facilitate education outcomes, but also skills needed for the workplace and lifelong skills in general. Some ICT such the Internet, email and digital media are now used routinely in many institutions across all sectors, primary, secondary and tertiary.

Since the early 1990s it has been a Victorian State government educational policy to introduce technology into the curriculum and equip students with computer knowledge (Snyder, 1997). In tertiary institutions where online learning is a feature of many courses, learning management systems such as WebCT have been adopted widely, and in some institutions having a component of online delivery has become mandatory for all courses. 
A new medium brings with it new challenges and opportunities for teachers and learners. For example, for educational theorists the changes brought about by using technology in education means the term "literacy" must be broadened to encompass these new skills or reflect the merging of old and new literacies. For practitioners, the challenge lies in making the new media meaningful and empowering to students.

This study investigated and compared the effectiveness of training on the reading comprehension of students when reading hypertexts with linear structure. In particular, the influence of training in metacognitive reading comprehension strategies on hypertext comprehension was evaluated, anticipating that training students to monitor their comprehension would result in enhanced reading comprehension for hypertext.

\section{Literature review}

\section{Hypertext and skills required to read critically}

There is a need for new skills required to decode texts presented in cyberspace but in some cases it is the amalgam of old and new. Burbules and Callister (1996, cited in Sutherland-Smith 2002a, p. 665) described reading on the Internet as an activity which 'extends thinking skills beyond the hierarchical, linear-sequential model that serves so well in the world of print media'.

Studies concur that hypertexts are different from traditional texts in terms of organisational patterns, multimodilty and linearity (Tindale, 2005). The effects these patterns have on the reader differ according to the ability of the reader. Reading hypertexts is not a generic activity. The literature shows that units within the Internet such as homepages and the way readers choose and follow links are parts of the cyberspace reading experience (Thurstun, 2004; Burbules, 1997).

Burbules (1997) pointed out that whilst the act of reading in itself is the same, hypertext reading is carried out in a different context. He called the act of reading in cyberspace "hyperreading" and the different context "the pragmatics of reading" (Burbules, 1997). Even though information is referred to as "pages", he pointed out that the speed, structure and presentation of webtexts are vastly different to traditional print texts. He also said that "surfing" the web indicates a quick skimming of texts in order to determine what is important. This is what Sutherland-Smith called the "snatch-and-grab" technique of reading (Sutherland-Smith, 2002a).

In general, hypertexts are described as being non-linear, even though there are hypertexts which are organised similarly to print texts. The information can be reached in different sequences, using links. Hypertexts can also be interactive, giving the reader much more control over reading and understanding than occurs with traditional texts. Indeed, in many cases the reader can become the writer by contributing to the text.

The visual element in web texts is another typical feature which adds to the complexity of reading in this context (Sutherland-Smith, 2002a, p. 665). Web literacy has been defined as a term for "finding, scanning, digesting, and storing Internet information" (Sutherland-Smith, 2002a, p. 663). Snyder (2002) states that for the first time in history, literacy encompasses written, oral and audiovisual modalities. A further dimension of hypertexts is that they can be updated regularly or frequently so the reader encounters 
a different text each time it is accessed (Sutherland-Smith, 2002b). Writing from a computer literacy perspective, Corbel states that hypertext reading requires "associative thinking", but reading print texts requires deep critical reading of a text (Sutherland-Smith, 2002b, p. 56).

All these features add new dimensions to the traditional notion of "literacy". Researchers agree that reading web texts involves expanding critical skills (Sutherland Smith, 2002a, p. 663). Henry (2006, p. 616) identifies 5 functions as being essential to "new literacy", which include locating information, critically evaluating its usefulness, synthesising information to answer those questions and communicating the answers to others. Skills in locating relevant information from within an ever increasing volume, and using search engines, are especially important.

Similarly, Martin (2003) states that from a practitioner's point of view the amount of wasted time when searching for information is noticeable and readers need guidance with this skill. Henry (2006) supports this finding. She found the major obstacle for students was that they were unable to successfully limit their search. This resulted in much wasted time and frustration as the volume of material was far too great for the learners to sift through. Henry concludes that some learners lacked the new literacy necessary to read and comprehend the results generated via their search engine. Furthermore Sutherland-Smith (2002a) mentions that it is crucial for teachers to instruct learners on how to best limit searches and suggested teachers use preprepared websites in order to facilitate this. Schneider (2005) also points out learners are unlikely to engage with hypertext without first being introduced to the structure. In addition, Zumbach (2006) concluded that navigational tools are not always helpful and further 'getting lost' in not unique to the hypertext environment.

Although some researchers caution there are difficulties which accompany this medium of instruction, studies show that when properly 'scaffolded', using hypertexts in the learning context can greatly enhance learning. For example, in his evaluation of the quality and use of hypermedia in the university sector, McKenna (2002) stresses that "effective learning requires scaffolding" (p. 625).

Educators in the English as a second language (ESL) have shown that online language learning tasks based on social constuctivist principles lead to collaborative and self directed learning (Gruba, 2004). Similarly, Jeon-Ellis, Debski and Wigglesworth (2005) explored the collaborative nature of task based learning with students studying French. The study looked at oral interaction used by French students when studying hypertexts in the classroom. The study supports previous findings that technology based tasks facilitate language learning. Furthermore, varying technological roles led students to become the experts in some areas of the language. The benefits of the informality and flexibility of the medium are also shown to be an advantage for learners as less emphasis is placed on 'accuracy' and more on meaning making (McPherson \& Murray, 2003). Moreover, Debski (2006) found out that online projects give learners access to authentic materials and interactions.

In the secondary school setting, Beavis (2001) explored the "expanding notions of text" by analysing interactions between year 8 students in a Melbourne secondary school. Two computer games were used to lead onto reading, writing and speaking activities. It was found that the students worked in a collaborative manner when problem solving opportunities arose from the discussions. The written tasks appeared to be 
"multifaceted, collaborative and collegial" (p.152). It was recommended to use these activities widely as they stimulate students' thinking and help them explore literacy.

Most researchers agree with the notion that skills required to decode hypermedia are different to conventional or print media and that these need to be refined by learners and educators alike. Thus, in some cases they require other skills (RAND Reading Study Group, 2001; Thurstun, 2004). An International Reading Association statement (2001, cited in Corio, 2003, p. 458) says that "traditional definitions of reading, writing, and viewing, and traditional definitions of best practice instruction - derived from a long tradition of book and other print media - will be insufficient".

Corio (2003) investigated the comprehension process for hypertexts. The author used the definition of comprehension set out by the RAND Reading Study Group Report (2001, also cited in Corio, 2003, p. 459) which defines reading comprehension as "the process of simultaneously extracting and constructing meaning through interaction and involvement with the written language". Therefore, in order to fully capture the reading comprehension process of webtexts which have different characteristics, the definition of reading comprehension must be expanded. This definition should include the recognition that reading on the Internet requires new thought processes and metacognitive skills.

Reading on the Internet requires skills which differ in terms of purpose, process and consequences (Corio, 2003). Purpose refers to the collaborative thinking skills needed to construct meaning from web texts and bringing sources together. The process skills are those needed to locate and evaluate the texts, including drawing on the connections between multiple sites. The consequences of reading are those skills outlined by the RAND Reading Study Group which include how the reader uses existing knowledge when reading new texts. With regards to knowledge, Corio (2003) says that web based reading has the potential for more diverse knowledge gain.

Like other texts, it is difficult to define hypertext in a unified or generic way; it is possible, however, to talk about general characteristics of this genre. In recent years at least some features of hypertexts have been consolidated. For example, the structure of homepages has been consolidated to the point where it can now be regarded as a text type which means some of its characteristics can be anticipated (Thurstun, 2004).

Research into hypertext assisted learning has investigated several factors that influence it (Snyder, 2002; Thurstun, 2004; Murray, 2005; Johnson-Glenberg, 2007). One, as shown above, is reading processes per se. Another aspect is the effect of structure, whether hierarchical or ill-structured, on reading comprehension. It has been found that more proficient readers are more challenged by ill-structured texts whereas poorer readers benefit from texts which are hierarchical in structure. Other factors come into play when considering hyperreading, for example, learner variables such as prior knowledge and cognitive styles. Other factors that impact on learning are patterns of navigation as they read.

\section{Metacognitive strategies to enhance reading comprehension}

Metacognition is defined as the knowledge and understanding a reader has about their thinking process while reading (Harvey \& Goudvis, 2000; Gunning, 2003). A major aspect of metacognition is monitoring, though these terms are sometimes being used 
synonymously. Monitoring is referred to the ability to both recognise when comprehension is not taking place and the ability to apply skills to repair this (Harvey \& Goudvis, 2003). Readers who have metacognitive skills are said to be proficient, aware, strategic or reflective readers. Those who do not possess these skills tend to be passive or tacit readers (Harvey \& Goudvis, 2003). When applying strategies, active readers will behave differently to passive readers.

There are many features that successful readers bring to the act of reading. Pearson et al (1992) outline the following:

- searching for connections;

- monitoring;

- repairing;

- discriminating between important and less important ideas;

- synthesising information within and across texts;

- drawing inferences;

- asking questions of themselves, the reading and the authors.

It is important to point out that many skills are used in tandem, for example inferring the main ideas of a text may mean the reader has to first summarise the different points. In other texts information can only be inferred by understanding the main points. Another issue is that standardised tests often ask questions about the main idea, whereas in real life texts have more than one idea. Therefore the choice of tests is important when teaching and assessing comprehension. Making inferences may be facilitated the by reader's existing knowledge, however misconceptions or inappropriate schemata can interfere with comprehension (Pearson, et al, 1992). With regards to repairing or regulating comprehension when it goes wrong, it is worth remembering that these are usually conscious skills whereas reading and understanding, when it is going well, are unconscious (Pearson, et al, 1992).

Models of teaching metacognition in the conventional written text context share similarities, and the examples vary in terms of depth and approach. It is obvious that any model should be adaptable to individuals or groups of learners. One well known instructional model was developed by Palincsar and Brown (1989, p.19). The authors identify "self regulated learning" as the ability of readers to be aware of the strategies they use when reading and "their ability to control their learning environment". In addition to having awareness of reading and metacognitive skills, readers are said to have real world knowledge. Palincsar and Brown (1989) identify six strategies which students can employ to aid and monitor their comprehension. These are:

1. Clarifying purpose of reading in order to identify the approach to reading such as skimming or more focused reading.

2. Making connections between known and new information presented in the text.

3. Giving more attention to the important part of the text.

4. Critically evaluating the content for consistency according to prior knowledge.

5. Using monitoring activities such as paraphrasing, self-questioning in order to check that comprehension is taking place.

6. Drawing and testing inferences such as making interpretations and predictions. 
The second model is the direct explanation of comprehension strategies, or DECS (Duffy, 2002). This model teaches individual strategies in an explicit and straightforward way. There are five components in the procedure:

1. Explicit description.

2. Modeling of strategy in action.

3. Collaborative use of the strategy.

4. Guided practice.

5. Independent use of the strategy.

There is much overlap between the two models presented. The instructional aspect of both models points to the importance of teaching strategies explicitly, and at the same time modeling and guiding students towards the independent use of the strategies. Teaching reading strategies does not end with the instruction class. It should be revisited over time in order to foster independent and critical readers.

McNamara and Shapiro (2005) stressed that understanding hypertexts is an essential part of classroom reading and that in today's society such texts are ubiquitous. Central to the writers' view is that understanding takes place by the reader's ability to interpret the linguistic signals in the texts. Therefore, they investigated how coherence can aid metacognitive strategies across texts. They applied Self Explanation Reading Training (SERT) in teaching the iSTART program and concluded that whilst not all strategies work for all learners, the provision of cohesive texts is one solution. The second one is to teach about hypertext structure as the hypertext design is also found to impact comprehension.

Thus, supported and meaningful use of hypertexts is both desirable and productive. It is obvious that more research into metacognition and hypertext reading is needed (Schneider, 2005; Johnson-Glenberg, 2007). The present study aims to add to the growing body of literature in this area and addresses explicit teaching of metacognitive strategies in the hypertext context.

\section{Methodology}

\section{Participants}

Thirty-eight students who commenced their first year Diploma within the Department of Horticulture and Environmental Science at Swinburne University of Technology (TAFE Division) were chosen to participate in the study. The sample was chosen on the basis that all the students signed the consent form and agreed to take part in the project. However 7 students withdrew from the project for various reasons and the final number of participants was 31 (14 male and 17 female students). The demographic reflected an average socio-economic background. The students did not have emotional difficulties or learning disabilities; their learning capacity was average; they attended the University regularly. Although the majority of students (27) had English as their first language, four students were of non-English speaking background.

\section{Procedures and data collection}

A Horticulture website was created about Land and Conservation management, comprising 16 web pages. One was an introductory page (the Home Page) and the 
other 15 pages consisted of 5 sessions relating to different aspects of River restoration management. The 15 pages all had hypertext links embedded into the text and were either links to text, audio or pictures. Reading tasks were developed for each text of varying length. The tasks were developed keeping in mind the skills the learners would be asked to practice and put into place. The structure of the pretest, training sessions and post-test sessions is shown in Table 1.

Table 1: Design of e-learning program

\begin{tabular}{|c|c|c|c|c|c|c|}
\multirow{3}{*}{ Session } & Text & Text length & Type & Number & \multicolumn{2}{|c|}{ Tasks } \\
\cline { 5 - 7 } & & in words & of link & of links & Questions & cloze \\
\hline \multirow{3}{*}{1} & 1 & 500 & Text & 5 & 5 & 5 gaps \\
\cline { 2 - 7 } & 2 & 500 & Picture & 5 & 5 & 5 gaps \\
\cline { 2 - 7 } & 3 & 500 & Audio & 5 & 5 & 5 gaps \\
\hline \multirow{3}{*}{2} & 1 & 300 & Text & 3 & 2 & 2 gaps \\
\cline { 2 - 7 } & 2 & 400 & Text & 4 & 3 & 3 gaps \\
\hline \multirow{3}{*}{3} & 1 & 500 & Text & 5 & 4 & 5 gaps \\
\cline { 2 - 7 } & 2 & 300 & Picture & 3 & 2 & 2 gaps \\
\cline { 2 - 7 } & 3 & 400 & Picture & 4 & 3 & 3 gaps \\
\hline \multirow{3}{*}{4} & 2 & 500 & Picture & 5 & 4 & 5 gaps \\
\cline { 2 - 7 } & 3 & 300 & Audio & 3 & 2 & 2 gaps \\
\hline \multirow{3}{*}{5} & 1 & 400 & Audio & 4 & 3 & 3 gaps \\
\cline { 2 - 7 } & 2 & 500 & Audio & 5 & 5 & 5 gaps \\
\cline { 2 - 7 } & 3 & 500 & Text & 5 & 5 & 5 gaps \\
\hline
\end{tabular}

The study was designed to be delivered over five 1.5 hour sessions on a weekly basis in Semester One, 2007. The first session consisted of a pretest and the last one was a post-test. In order to compare results of pretest and post-test, the texts were of the same length and had the same number of links in each text. Also all hypertexts had the same readability level, as they were written based on reading material used for this level of study.

Training was based on the principles of explicit or direct instructions DECS (Duffy, 2002) and was as follows.

1. Explicit description: each skill is to be defined explicitly.

2. Modeling of strategy in action: each skill is modeled by the instructor using examples of materials and texts to which it can be applied.

3. Collaborative use of the strategy: the strategy is used in action.

4. Guided practice: students practice under instructor's supervision.

5. Independent use of the strategy: students are directed to use the skills independently.

The skills which were explained and modeled were the following: prediction, summarising, paraphrasing, visualising and questioning.

All sessions were set up so that the learners would receive instructions on how to approach reading hypertexts critically. They were asked to answer questions; literal, inferential and critical. For example, literal questions were like "What are the main features of wetlands and waterways?" (session 1, text 2), or "Why are salt concentrations in waterways low in winter and high in summer?" (session 5, text 1). At 
the literal level, readers comprehend the ideas stated explicitly in the text. Literal comprehension requires readers to operate on the surface level of text (Davis \& Lass, 1996).

At the inferential level, readers 'go beyond' relationship stated explicitly in the text. They predict or infer unstated relationships. Inferential comprehension occurs as readers make predictions or develop ideas (Davis \& Lass, 1996). Examples of inferential questions included: "Why does riparian land tend to be exploited?" (session 1 , text 1 ), or "Why is riparian vegetation essential for regulating water temperature?" (session 5, text 3).

At the critical level, students read beyond the lines to make associations with other knowledge, to solve problems and to modify existing perception. Whereas literal comprehension deals mainly with facts, and inferential comprehension with interpretation, critical comprehension is concerned with opinion, and necessitates the use of both literal and inferential skills (Davis \& Lass, 1996; Gunderson, 1991). Critical questions were as follows "What are the consequences of high salinity within our wetlands and waterways?" (session 5 , text 1 ) or "What is the importance of wetlands in the ecological system?" (session 1, text 3). Also, a cloze or sentence completion task was given to students. In addition, during the training sessions the learners were asked to complete self evaluation reports.

The three training sessions were delivered as follows. In the first session the trainer gave feedback on the pretest session, highlighting skills which needed to be improved as well as areas where learners performed well. The trainer gave explicit explanation of the steps necessary to achieve maximum comprehension using the skills of paraphrasing, summarising, predicting, visualising and questioning. Next the trainer used a talk through procedure in which the skill is applied to text and reviewed the skills. Individual students were called upon or at least encouraged to contribute to the explanation. The next step required the students to work in small groups in order to practise the different strategies. The trainer gave feedback as appropriate and encouraged a group discussion after the learners had completed practice tasks. A review of the strategies was conducted at the end of the session.

During the second session the trainer aimed at consolidating the strategies introduced in the previous section. The learners reviewed the steps and further practiced with texts. The trainer monitored this process and gave individual as well as group feedback. The aim of this session was to encourage the application of the strategies learned. During the final training session the learners reviewed steps to enhance reading comprehension. The skills were again applied using texts and the learners were directed towards extending these skills. The trainer used modeling with talk through procedures. Students worked independently in this session. Finally the trainer reviewed strategies and gave individual feedback.

The system of assessment of each comprehension task was as follows. For answering the questions tasks, accuracy of the answer and the ability to think critically (where applicable) were assessed. One point was given for a correct and complete answer which also demonstrated critical thinking ability; half a point was given for partially completed answer, zero points for an incomplete or incorrect answer. The maximum overall score for pre-test and post-test was 10 points (maximum 5 points for comprehension questions and maximum 5 points for the cloze). 


\section{Results and discussion}

The means, standard deviations, skewness and kurtosis for the two types of reading comprehension: expressive comprehension (assessed using literal, inferential and critical expressive questions) and recognition comprehension (assessed using a cloze task) before and after training sessions for hypertexts with text, picture or audio links, are shown in Tables 2 and 3 respectively. The measures of skewness are within two standard errors of skewness and do not differ from a normally distributed set of scores according to the criteria set by Tabachnik and Fidell (1996). Similarly, the measures of the kurtosis statistic are within two standard errors of kurtosis and do not differ from a normally distributed set of scores according to the criteria set by Tabachnik and Fidell (1996).

Table 2: Means, standard deviations, skewness and kurtosis for a hypertext comprehension before training sessions

\begin{tabular}{|l|c|c|c|c|c|c|c|c|}
\hline \multirow{2}{*}{$\begin{array}{c}\text { Type of } \\
\text { link }\end{array}$} & \multicolumn{9}{|c|}{ Compressive } & \multicolumn{5}{c|}{ Recognition } \\
\cline { 2 - 9 } & mean & SD & Skewness & Kurtosis & mean & SD & Skewness & Kurtosis \\
\hline Text & 3.24 & 0.84 & -0.21 & 0.87 & 3.61 & 0.66 & -0.53 & 0.20 \\
\hline Picture & 3.06 & 1.00 & -0.24 & -1.07 & 3.48 & 0.90 & -0.41 & -0.07 \\
\hline Audio & 2.87 & 1.08 & -0.45 & 0.36 & 3.24 & 0.79 & -0.82 & 0.80 \\
\hline
\end{tabular}

Table 3: Means, standard deviations, skewness and kurtosis for a hypertext comprehension after training sessions

\begin{tabular}{|l|c|c|c|c|c|c|c|c|}
\hline \multirow{2}{*}{$\begin{array}{c}\text { Type of } \\
\text { link }\end{array}$} & \multicolumn{9}{|c|}{ Comprehension score after training } \\
\cline { 2 - 9 } & mean & SD & Skewness & Kurtosis & mean & SD & Skewness & Kurtosis \\
\hline Text & 3.96 & 0.92 & -0.48 & -0.72 & 4.21 & 0.68 & -0.49 & -0.89 \\
\hline Picture & 3.53 & 0.78 & 0.11 & -0.44 & 3.89 & 0.83 & -0.58 & -0.02 \\
\hline Audio & 3.19 & 0.86 & -0.27 & -0.94 & 3.79 & 0.77 & -0.11 & -0.27 \\
\hline
\end{tabular}

To estimate the validity of the comprehension tasks, associations between comprehension of hypertext before training (s1) and comprehension of a hypertext after training ( $(55)$ for various texts $(\mathrm{t} x)$ and tasks $(\mathrm{t})$ were examined. Correlation coefficients (Pearson product-moment correlation coefficient) for the above variables are shown in Table 4 . The data indicate positive correlations between comprehension of hypertext before and after training sessions for hypertexts with various types of links and tasks. These data provide an estimate of the validity of the comprehension tasks. They also show that the strategy training did not alter the rank order of the students in each condition.

Table 4: The intercorrelation matrix

\begin{tabular}{|c|c|c|c|c|c|c|}
\hline & s5tx1t1 & s5tx1t2 & S5tx2t1 & $s 5 t \times 2 t 2$ & S5tx3t1 & $s 5 t \times 3 t 2$ \\
\hline s1tx1t1 & $0.470^{\star *}$ & & & & & \\
\hline s1tx1t2 & & $0.534^{* *}$ & & & & \\
\hline s1tx2t1 & & & $0.588^{\star *}$ & & & \\
\hline s1tx2t2 & & & & $0.834^{* *}$ & & \\
\hline s1tx3t1 & & & & & $0.782^{* *}$ & \\
\hline s1tx3t2 & & & & & & $0.873^{\star *}$ \\
\hline
\end{tabular}


The influence of strategy training on text comprehension was analysed using paired ttest. The results demonstrate (Table 5) that for each type of hypertext (containing text, picture or audio links) training students to apply metacognitive strategies when reading hypertext influenced both expressive and recognition comprehension. Trends in expressive and recognition comprehension for hypertexts with different types of links are shown in Figures 1 and 2 respectively.

Table 5: The influence of strategy training on text comprehension

\begin{tabular}{|c|c|}
\hline & $\mathrm{T}$ \\
\hline s1tx1t1 - s5tx1t1 & $-4.434^{* *}$ \\
\hline s1tx1t2 - s5tx1t2 & $-5.105^{* *}$ \\
\hline $\mathrm{s} 1 \mathrm{t} \times 2 \mathrm{t} 1-\mathrm{s} 5 \mathrm{t} \times 2 \mathrm{t} 1$ & $-3.115^{* *}$ \\
\hline $\mathrm{s} 1 \mathrm{t} \times 2 \mathrm{t} 2-\mathrm{s} 5 \mathrm{t} \times 2 \mathrm{t} 2$ & $-4.429^{* *}$ \\
\hline $\mathrm{s} 1 \mathrm{t} \times 3 \mathrm{t} 1-\mathrm{s} 5 \mathrm{t} \times 3 \mathrm{t} 1$ & $-2.651^{*}$ \\
\hline $\mathrm{s} 1 \mathrm{t} \times 3 \mathrm{t} 2-\mathrm{s} 5 \mathrm{t} \times 3 \mathrm{t} 2$ & $-7.733^{* *}$ \\
\hline${ }^{* *} \mathrm{p}<0.01$ level (2-tailed) & \\
${ }^{*} \mathrm{p}<0.05$ level (2-tailed) &
\end{tabular}

The results of this study indicate that expressive comprehension under the metacognitive training conditions was enhanced for a hypertext. It demonstrated that while reading, students monitored their progress, discriminated between important and less important ideas and asked questions of themselves, the reading and the authors. Also the students' improved recognition comprehension in the hypertext context confirms the readers' ability to monitor their progress, search for connections, repair comprehension and synthesise information within and across hypertexts. It means that during the reading of hypertexts, students were able to keep the whole context in mind.

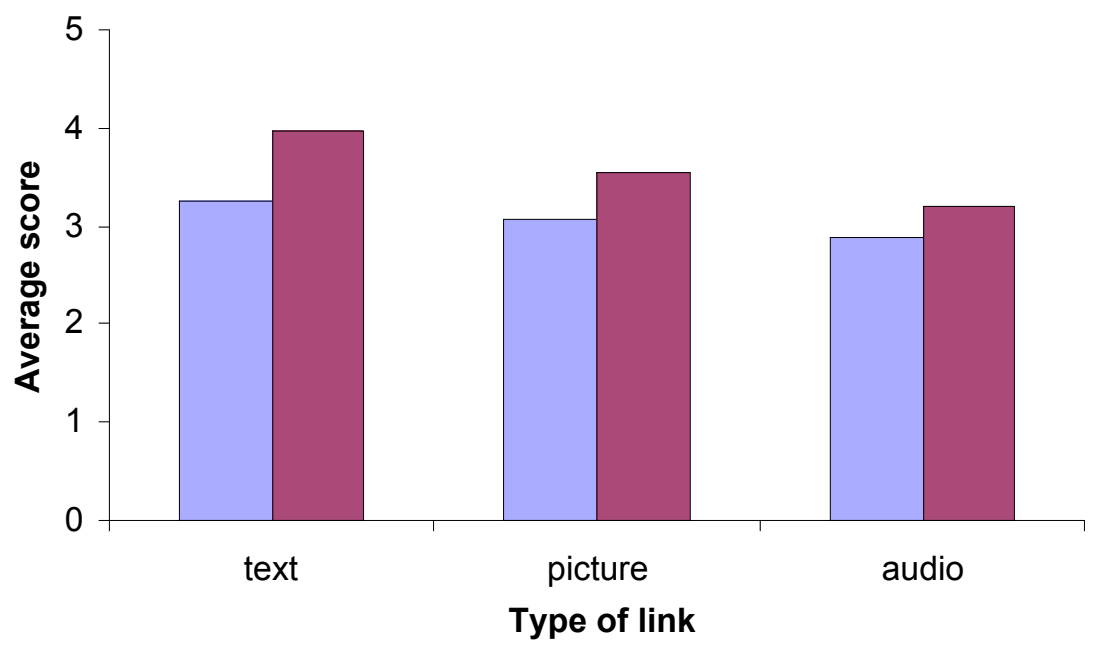

$\square$ before training sessions $\square$ after training sessions

Figure 1: Trend in expressive comprehension for hypertexts with different types of links 


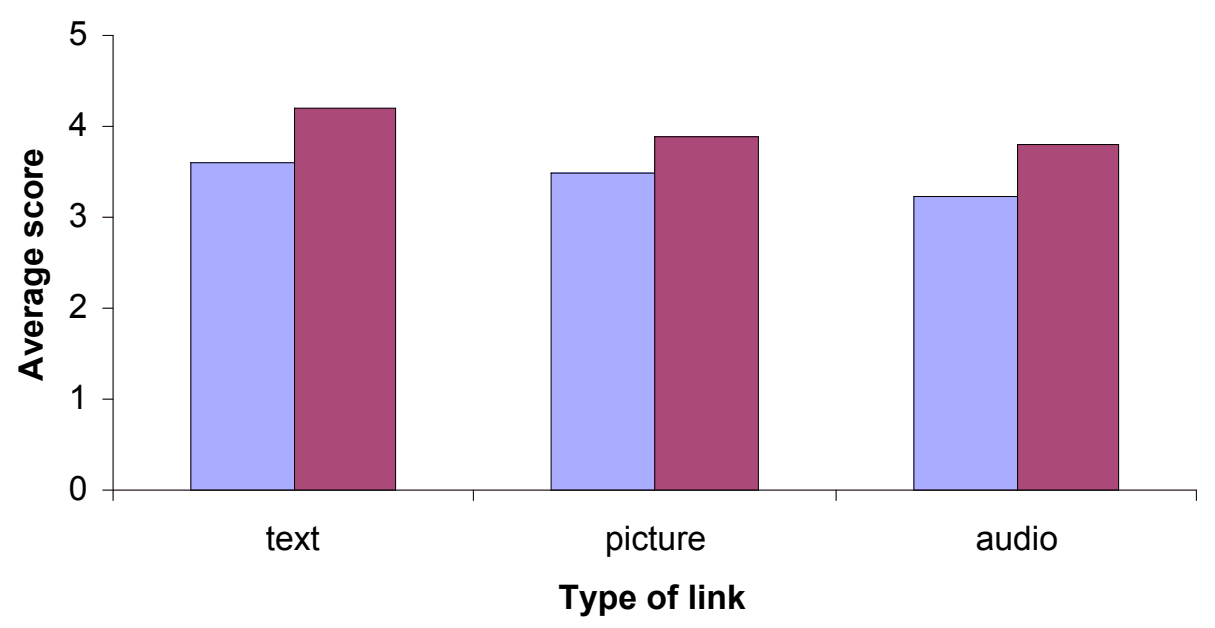

$\square$ before training sessions $\square$ after training sessions

Figure 2: Trend in recognition comprehension for hypertexts with different types of links

These findings provide additional support for the use of instruction in metacognitive reading comprehension strategy in the hypertext environment. They also extend the findings of similar investigations conducted by numerous researchers on comprehension of a conventional written text while using this strategy (Harvey \& Goudvis, 2000; Gunning, 2003; Pearson et al, 1992). Overall, these data indicate support for the hypothesis that training to apply metacognitive reading strategies was associated with improvement in the expressive and recognition comprehension of hypertexts with text, picture and audio links.

\section{Conclusions}

Technology has ushered in a paradigm shift in our ways of reading, learning and teaching. Reading hypertexts requires new skills which educators have to address. A number of studies have demonstrated the importance of teaching metacognitive skills to enhance reading comprehension in the conventional written text context. However, metacognitive strategies for hypertext have not been studied extensively. This study adds a new dimension to the existing body of research by investigating the influence of explicit teaching of metacognitive strategies on hypertext comprehension.

The results suggest that teaching of metacognitive strategies is transferable to the hypertext context. Furthermore, training to apply metacognitive reading strategies may enhance both overall comprehension and expressive and recognition comprehension for hypertexts with text, picture and audio links. Step by step instructions tend to be of paramount importance when teaching in the hypertext context. Initially, instructions had been mastered by students and applied to reading hypertexts specifically designed for learning and teaching purposes. This gave them an opportunity to practise their hypertext reading skills and gain confidence when reading in subject-specific material, before applying these skills to any kind of hypertext. Finally, reading hypertexts at literal, inferential and critical levels facilitated 
comprehension as the students read hypertexts carefully for literal comprehension, and made connections between facts and the subject, as well as applying what they had learnt to new situations.

\section{Acknowledgements}

This research was funded by the Professional Development Unit, Swinburne University of Technology, TAFE Division. Also special appreciation must be given to Elizabeth Norman, the Study Support program coordinator, for her helpful comments and advice on the draft of this paper. The authors thank Jennifer Woodward for providing audio records for the website. Photographs for the website were provided by Patricia Watkins, Robyn Hill and Ian Reynolds as well as taken from the public domain.

\section{References}

Beavis, C. (2001). Digital culture, digital literacies. In C. Durrant \& C. Beavies (Eds.), P(ict)ures of English teachers, learners and technology (pp. 145-161). South Australia: Wakefield Press.

Burbules, N. (1997). Rhetorics of the web: Hyperreading and critical literacy. In I. Snyder (Ed.), Page to screen: Taking literacy into the electronic era (pp. 102-122). Sydney: Allen \& Unwin.

Corio, J. (2003). Exploring literacy on the Internet. Reading comprehension on the Internet: Expanding our understanding of reading comprehension to encompass new literacies. The Reading Teacher, 56(5), 458-464.

Davis, B. G. \& Lass, B. (1996). Elementary reading: Strategies that work. Allyn and Bacon.

Debski, R. (2006). Project-based language teaching with technology. Sydney AMEP Research Centre.

Gruba, P. (2004). Designing tasks for online collaborative language learning. Prospect, 19(2), 72 79. [verified 14 May 2008] http:/ / www.ameprc.mq.edu.au/docs/prospect_journal/ volume_19_no_2/19_2_5_Gruba.pdf

Gunderson, L. (1991). ESL literacy instruction: A guidebook to theory and practice. Englewood Cliffs, NJ: Prentice Hall.

Gunning, T. G. (2003). Building literacy in the content areas. London: Oxford University Press.

Harvey, S. \& Goudvis, A. (2000). Strategies that work: Teaching comprehension to enhance understanding. Stenhouse Publishers.

Henry, L. A. (2006). SEARCHing for an answer: The critical role of new literacies while reading the Internet. The Reading Teacher, 59(7), 614-627.

Jeon-Ellis, G., Debski, R. \& Wigglesworth, G. (2005). Oral interaction around computers in the project-oriented CALL classroom. Language and Technology, 9(3), 121-145. [verified 15 May 2008] http:/ / llt.msu.edu/vol9num3/jeon/default.html

Johnson-Glenberg, M. C. (2007). Web-based reading comprehension instruction: Three studies of 3D-readers. In D. McNamara (Ed.), Reading comprehension strategies: Theories, interventions, and technologies (pp. 293-324). Abingdon: Lawrence Erlbaum.

Kellner, D. (2002). Technological revolution, multiple literacies, and the restructuring of education. In I. Snyder (Ed.), Silicon literacies: Communication, innovation and education in the electronic age (pp. 154-169). London: Routledge.

McKenna, B. (2002). Hype about hypertext. In C. Candlin (Ed.), Research and practice in professional discourse (pp. 609-636). Hong Kong: City University of Hong Kong. 
McNamara, D. \& Shapiro, A. (2005). Multimedia and hypermedia solutions for promoting metacognitive engagement, coherence and learning. Journal of Educational Computing Research, 33(1), 1-29.

McPherson, P. \& Murray, D. (2003). Communicating on the Net. Sydney AMEP Research Centre.

Murray, D. \& Macpherson, P. (2005). Navigating to read - reading to navigate. Sydney AMEP Research Centre.

Palincsar, A., Sullivan, A. \& Brown, A. L. (1989). Instruction for self-regulated reading. In B. L. Resnick \& L. E. Klopfer (Eds.), Toward the thinking curriculum: Current cognitive research (pp. 19-39). ASCD.

Pearson, P., Roehler, L. R., Dole, J. A. \& Duffy, G. (1992). Developing expertise in reading comprehension. In S. J. Samuels \& A. E. Farstrup (Eds.), What research has to say about reading instruction (2nd ed., pp. 145-199). Delaware: International Reading Association.

RAND Reading Study Group (2001). Reading for understanding: Toward a RED Program in reading. [verified 15 May 2008] http:/ / www.rand.org/multi/achievementforall/reading/readreport.html

Schneider, R. (2005). Hypertext narrative and the reader: A view from cognitive theory. European Journal of English Studies, 9(2), 197-208.

Snyder, I. (Ed.) (1997). Page to screen: Taking literacy into the electronic media. Sydney: Allen \& Unwin.

Snyder, I. (2002). Silicon literacies: Communication, innovation and education in the electronic age. London: Routledge.

Sutherland-Smith, W. (2002a). Weaving the literacy web: Changes in reading from page to screen. The Reading Teacher, 55(7), 662-669.

Sutherland-Smith, W. (2002b). Web-text: Perceptions of digital reading skills in the ESL classroom. Prospect, 17(1), 55-70. [verified 15 May 2008] http: / / www.ameprc.mq.edu.au / docs/prospect_journal/volume_17_no_1/17_1_4_Sutherland.pdf

Tabachnik, G. B. \& Fidell, S. L. (1996). Using multivariate statistics. New York: Harper Collins College Publishers.

Thurstun, J. (2004). Teaching and learning the reading of homepages. Prospect, 19(2), 56-80. http:// www.ameprc.mq.edu.au/docs/prospect_journal/volume_19_no_2/19_2_4_Thurston.pdf

Tindale, J. (2005). Reading print and electronic texts. In D. Murray (Ed.), Navigating to read reading to navigate (pp. 2-26). Sydney AMEP Research Centre.

Zumbach, J. (2006). Cognitive overhead in hypertext learning re-examined: Overcoming the myths. Journal of Educational Multimedia and Hypermedia, 15(4), 411-432.

Dr Elena Verezub (BEd, Candidate of Science in Ed Psych, PhD in Education (Melb)) is a Language and Academic Skills Advisor at Swinburne University of Technology, Australia. She has over 15 years of teaching experience in TESOL, education and educational psychology, both in Australia and Ukraine. Elena's professional and research interests include e-learning and hypertext literacy; study expectations in TAFE and higher education environments; language and academic skills; psychological aspects of text memorisation. Email: everezub@swin.edu.au

Dr Elena Verezub, Ms Vittoria Grossi, Ms Kerry Howard, Ms Patricia Watkins Swinburne University of Technology, PO Box 218, Hawthorn VIC 3122, Australia 